\title{
Spatial economic effects of the use of local resources: case of cement-bonded wood fiber blocks
}

\author{
Nikolai Kolesnikov ${ }^{1, *}$ and Natalia Kolesnikova ${ }^{2}$ \\ ${ }^{1}$ Institute of Economics of the Karelian Research Centre of the Russian Academy of Sciences, pr. \\ Nevskogo, 50, Petrozavodsk, 185030, Russia \\ ${ }^{2}$ Petrozavodsk State University, pr. Lenina 33, Petrozavodsk, 185910, Russia
}

\begin{abstract}
Use of local resources as a replace for resources brought from outside the region impacts the spatial allocation of value-added chains and causes spatial economic effects. Region benefits from multiplier economic effect caused by extra production volumes added within the region. Effects for national economy could be controversial if the replacing production is less efficient. The article considers the case of cement-bonded wood fiber construction blocks to be produced in the Republic of Karelia, Russia. Economic multiplier regional effects are assessed applying social accounting matrix approach.
\end{abstract}

\section{Introduction}

The article considers the introduction of production of cement-bonded wood fiber blocks in the Republic of Karelia, Russia. Cement-bonded wood fiber (CBWF) is relatively lightweight cement composite. In terms of strength, heat insulation and weight per volume unit, CBWF has properties similar to aerated concrete (AC), and thus technically CBWF blocks could serve as a substitute for AC blocks that currently dominate the market of construction blocks for light walls. Components required for the production of CBWF are wood in the form of small particles - chips or sawdust, cement, and additives. Technical issues of CBWF production are covered by Małaszkiewicz \& Sztukowska [6]. Wood chips and sawdust are produced locally as they are by-products of numerous wood processing plants in the Republic of Karelia i.e. the region has competitive advantage for producing CBWF blocks as per proximity of the key resource. This advantage does not lead to launching large production projects due to their relative inefficiency as compared to AC blocks production.

Launching of new production that produces a substitution for imported resource in a region virtually relocates value added chains from another region - in our case from Leningrad Oblast to the Republic of Karelia. Expansion of economic activities within value added chains generates multiplier economic effects for the region. The size of the effect could be greater than amount of funding required to provide price competitiveness for CBWF blocks. In that connection the size of the effects should be evaluated and compared to the

\footnotetext{
*Corresponding author: nikolaikolesnikov@yandex.ru
} 
funding required in order assess the feasibility of subsidizing the local production of CBWF blocks. The aim of the article is to assess multiplier regional effect caused by introduction of CBWF blocks in the Republic of Karelia.

\section{Methodology}

For the current research, we employed a method of Social Accounting Matrix (SAM) as a methodological approach for assessing regional economic effects. SAM approach is a recognised tool for assessing economic effects based on input-output analysis. This approach is implemented by Philippidis et al. [7] to assess effects of bioeconomy development. Economic multipliers of forest products industry are investigated by Dahal et al. [3]. Within SAM approach, region is recognised as a spatially distinctive economic entity viewed as an equilibrium system of interrelated and interacting sectors. Economic interactions inside the regional economic system are described as flows of values (money, and goods and services expressed in terms of money). Economic interactions of a region with other regions within the national economy are described as flows of values between region's sectors on one side and national economy's sectors on the other side.

The key advantage of SAM approach is that it allows to compute aggregate, or multiplier, impact on regional economic system caused by a change occurred in some specific sector that lead to changes in all other sectors of region's economy.

The composition of sectors of regional economic system within the SAM approach may vary depending on the nature of the research task. However, the composition should reflect the basic sectors - production and commercial services, households, government (or public sector). Depending on the aim of the research, set of sectors may be extended to represent as detailed composition as required by researcher. The composition of sectors is assumed to be rigid meaning that the structure of regional economy is not assumed to change. That assumption is correct for assessing the short term effects while in a long run shifts in the composition of sectors must be considered. The aim of our research is to assess economic effects in the short term, therefore we assume the composition of sectors being rigid.

The model of regional economy within SAM approach is described by matrixes $\mathbf{A}, X$ and $Y$. $X$ is a vector whose elements correspond to total revenues by each sector. $Y$ is a vector whose elements correspond to net revenues from outside the region by each sector. $\mathbf{A}$ is a square matrix whose columns represent a structure of expenditures by each sector. Values in matrix $\mathbf{A}$ are constants, elements in $X$ and $Y$ are variables. The equilibrium of regional economy is described by a system of linear equations (1).

$$
\mathbf{A} X+Y=X
$$

For our research, we suggest to use a basic model of regional economy that includes five sectors: production of the local resource whose impact on regional economic system is assessed; aggregate sector that includes all other productions of goods and services in the region (competitive production); sector whose goods and services are not produced within the region and fully brought from outside the region (non-competitive production); households; and government. Government is divided into two subsectors corresponding to federal and regional budgets.

In terms of the suggested model the effect of the introduction of the local production is expressed in the change of the parameters of the model. Mathematically, we have to solve the system (1) and find the values of $X$ and $Y$ elements given that $y_{1}=\mathbf{V}$ where $\mathbf{V}$ is some volume of imported resources being replaced by the local production expressed in money units e.g. 100 thsd dollars. Depending on the local economic settings other limitations may apply to the model. 
The effect for a region is defined by the change of households income and/or regional tax revenues. Within the model, these changes are expressed by the values of corresponding elements of vector $X$.

The local resource as per the case investigated within the current work is CBWF blocks to be produced in the Republic of Karelia, Russia. These blocks are to be used as a substitute for AC blocks that are produced in the neighbouring region and currently hold the major market share in the region.

To build a system of linear equations (1) we have to define matrix A representing structure of expenditures for each sector. According to authors' calculations based on prices [9], wages [11] and taxation [4] information as of July 2018 the structure of expenditures for average CBWF blocks producer operating in the Republic of Karelia would be as follows: $17 \%$ for competitive products i.e. local goods and services (wood, electricity, water supply and transport services, premises rent), $30 \%$ for non-competitive products (equipment, cement and additives), $32 \%$ for wages, $8 \%$ for regional taxes, and $13 \%$ for federal taxes.

Structure of expenditures by competitive production sector in the Republic of Karelia cannot be calculated directly due to the absence of proper data. Literature review gives no information on this issue. We have hold expert interviews to address this question. According to experts consensus opinion competitive production sector in the Republic of Karelia spends $0.1 \%$ for AC or CBWF blocks, $17 \%$ for its own products, $39 \%$ for non-competitive products, $23 \%$ for wages, $5.7 \%$ for regional taxes, and $15.2 \%$ for federal taxes.

Non-competitive sector holds all its expenditures outside the region that means the element in the matrix A located on the intersection of the row and the column corresponding to non-competitive sector equals to 1 (or $100 \%$ ).

Estimation of the structure of spendings by households in the Republic of Karelia can be compiled from statistical data [10]. Households spendings for direct purchases of construction blocks are very small and can be neglected. $27 \%$ of total households income is spent for competitive sector products, $72 \%$ for non-competitive sector products, $0.2 \%$ for federal taxes and $0.8 \%$ for regional taxes (excluding income taxes paid for employees by employers).

Structure of spendings by regional budget is assessed based on official reports [8]. Regional authorities do not spend money for AC or CBWF blocks. $42.5 \%$ of their spendings come to competitive sector, $16 \%$ come to non-competitive sector, and $41.5 \%$ is transferred to households.

Extra income obtained by federal budget as tax payments from introduced production of CBWF blocks would not increase spendings by federal government on the territory of the region. In that connection, in the structure of spendings $100 \%$ is recorded to the federal government itself.

The data on the structure of expenditures of the sectors is congregated to compile matrix A (Table 1).

Suppose $y_{1}=100$ meaning that we are finding the multiplier effect of replacing imports of AC blocks in the volume of 100 money units by local production of CBWF blocks.

We should consider other settings to reflect in the model. The increase in production of CBWF blocks does not assume any changes in off-region transactions by competitive production sector, therefore $y_{2}=0$. The products of non-competitive sector are fully brought from outside the region, therefore $y_{3}=-\sum \mathbf{a}_{3 i} x_{i}$. The increase in production of CBWF blocks does not lead to any changes in transfers to or from the region made by households and regional government, therefore $y_{4}=0, y_{5}=0$. Spendings by federal government stay unchanged, i.e. additional volume of federal tax payments fully goes to federal budget outside the region, therefore $y_{6}=-\sum \mathbf{a}_{6 i} x_{i}$. 
Table 1. Matrix A

\begin{tabular}{|c|c|c|c|c|c|c|c|}
\hline \multicolumn{2}{|c|}{ Sector } & 1 & 2 & 3 & 4 & 5 & 6 \\
\hline 1 & CBWF blocks producer & 0 & 0.001 & 0 & 0 & 0 & 0 \\
\hline 2 & Competitive production & 0.17 & 0.17 & 0 & 0.27 & 0.425 & 0 \\
\hline 3 & Non-competitive production & 0.30 & 0.39 & 1 & 0.72 & 0.16 & 0 \\
\hline 4 & Households & 0.32 & 0.23 & 0 & 0 & 0.415 & 0 \\
\hline 5 & Regional government & 0.08 & 0.057 & 0 & 0.008 & 0 & 0 \\
\hline 6 & Federal government & 0.13 & 0.152 & 0 & 0.002 & 0 & 1 \\
\hline
\end{tabular}

The solution of the system (1) for the given case is as follows:

$X^{\mathrm{T}}=[100.04 ; 40.89 ; 0 ; 45.86 ; 10.70 ; 0]$

$Y^{\mathrm{T}}=[100 ; 0 ;-80.69 ; 0 ; 0 ;-19.31]$

The results of the calculations mean that the replacement of imported AC blocks in the volume of 100 money units by locally produced CBWF blocks would cause the multiplier effect in the regional economic system expressed, in particular, in the households income increased by 45.9 money units, and regional government revenues increased by 10.7 money units.

Table 2. Matrix A with subsidies

\begin{tabular}{|c|c|c|c|c|c|c|c|}
\hline \multicolumn{2}{|c|}{ Sector } & 1 & 2 & 3 & 4 & 5 & 6 \\
\hline 1 & CBWF blocks producer & 0 & 0.001 & 0 & 0 & 0 & 0 \\
\hline 2 & Competitive production & $0.17 *(1-s)$ & 0.17 & 0 & 0.27 & 0.425 & 0 \\
\hline 3 & Non-competitive production & $0.30 *(1-s)$ & 0.39 & 1 & 0.72 & 0.16 & 0 \\
\hline 4 & Households & $0.32 *(1-s)$ & 0.23 & 0 & 0 & 0.415 & 0 \\
\hline 5 & Regional government & $0.08 *(1-s)+s$ & 0.057 & 0 & 0.008 & 0 & 0 \\
\hline $5 \mathrm{a}$ & $\begin{array}{c}\text { Tax payments to regional } \\
\text { government }\end{array}$ & $0.08 *(1-s)$ & & & & & \\
\hline $5 \mathrm{~b}$ & $\begin{array}{c}\text { Subsidies from regional } \\
\text { government }\end{array}$ & $s$ & & & & & \\
\hline 6 & $\begin{array}{c}\text { Federal government } \\
6\end{array}$ & $0.13 *(1-s)$ & 0.152 & 0 & 0.002 & 0 & 1 \\
\hline
\end{tabular}

All calculations above are made at assumption that the price of local production of CBWF blocks is the same as the price of AC blocks including delivery to the region. In fact, this is not correct. CBWF blocks cost about 10\% more than AC blocks. This is the major reason why CBWF blocks are not produced in the Republic of Karelia at any considerable scale. Regional government may consider spend part of (potentially) increased tax revenues for subsidizing the local production in order to compensate the price difference. In terms of the model, subsidies are counted in the matrix $\mathbf{A}$ as additional element $s$ (Table 2). The value of $s$ reflects the share of CBWF blocks producer's costs covered with subsidies. The value of $s$ 
is negative or equals to zero as according to the logic of the model it is viewed as "reverse expenditure".

We may find the dependency between $s$ and the multiplier effect for the regional government (Figure 1). That effect includes increased tax revenues from all sectors with expenses for subsidizing the local producer deducted. Hence, the value of effect for the regional government is the value of $x_{5}$.



Fig. 1. Multiplier effect for the regional government.

Multiplier effect for the regional government $x_{5}$ turns from positive to negative value at the point of $s=-0.114$. That means regional government may spend money for subsidizing the local producer of CBWF blocks covering up to $11.4 \%$ of the market price for CBWF blocks and still gain positive effect in the form of increased tax revenues. If subsidies exceed $11.4 \%$ the multiplier effect for the regional government would not cover expenses for subsidies.

\section{Results}

Local production of CBWF blocks in the Republic of Karelia may partly replace on the regional market $\mathrm{AC}$ blocks brought from outside the region. However the cost of CBWF blocks is higher than that of AC blocks i.e. the local production of CBWF block is less efficient as compared to AC blocks produced in other regions of Russia. CBWF blocks are uncompetitive by price to AC blocks that is the obstacle to the unfolding of local production. Regional government may support local producer of CBWF blocks with subsidies compensating part of its expenses by e.g. tax exceptions or direct transfers.

Local production of CBWF blocks would generate multiplier effect for the regional economic system by provoking activities in other sectors within the value added chains. For the regional government, the effect manifests in tax revenues increased by 10.7 roubles per 100 roubles of replaced AC blocks assuming no subsidies are granted to the local producer. If subsidies are granted, the effect for the regional government would still be positive provided that subsidies do not exceed $11.4 \%$ of the market price for CBWF blocks. In other words, regional government may support local production of CBWF blocks that is $11.4 \%$ less efficient compared to extra-regional production of $\mathrm{AC}$ blocks at no cost for regional budget. Hence, supporting inefficient local production could generate no losses for regional budget due to multiplier effect. If local production is not 'too inefficient' its subsidizing could be even 'profitable' for regional government.

Production of AC blocks in Russia is concentrated in several locations at large-scale production sites i.e. the production is spatially concentrated. Partial replacement of their production volumes by introduction of $\mathrm{CBWF}$ blocks production outside AC-producing 
regions would lead to lesser spatial concentration of AC/CBWF blocks production (both blocks are substitute products for each other). That means more even allocation of economic activities which is generally regarded as one of the major aims of spatial cohesion policy as in Russia [5] so in EU [2].

From the national economy's perspective, replacing part of relatively efficient production of AC blocks with relatively inefficient production of CBWF blocks causes direct loss of overall economy's efficiency. Lesser efficiency would mean lesser international competitiveness of national economy. At the age of globalization, when capital easily breaks away from its national roots, low competitiveness may lock national economy in the lagging behind position for the long term.

Within the current research, only effects that has economic nature are explored. Introduction of production of CBWF blocks may also have social and environmental effects that may be expressed in economic terms and therefore included in the assessment. Social effect could be e.g. reduction of unemployment in the locality where the new production is launched. Reduction of unemployment can be evaluated in economic terms as a reduction of expenses for unemployment benefits paid from public funds. Environmental effects are linked to the technology of production of CBWF as it utilises wood waste that resides after wood processing. Approaches to environmental and social assessment of biomass projects are reviewed by Cambero and Sowlati [1]. Effects of social and environmental nature are not covered with the current research.

\section{Conclusion}

CBWF blocks as per their technical characteristics may serve as a substitute product for AC blocks that currently dominate national market of construction blocks in Russia. Technological process of CBWF production includes utilisation of wood waste residuals (wood chips or sawdust) that are produced in significant volumes as a side product in the Republic of Karelia. Despite the abundant supply of the major component, CBWF blocks are not produced at any significant volume in the region. The major obstacle for introduction of production of CBWF blocks is that the cost of production is about $10 \%$ higher as compared to AC blocks.

Regional government of the Republic of Karelia may consider subsidizing local producer(s) of CBWF blocks rationalizing by comparing expenditures for subsidies to multiplier effect expressed in increased tax incomes from all sectors of regional economy. If subsidies required to provide price competitiveness to CBWF blocks do not exceed $11.4 \%$ of the market price, regional government would gain net surplus. Multiplier effect for households income in the region would be positive as well. Despite positive effects for the regional economy, the effect in terms of national economy's efficiency and competitiveness could be negative. The contradiction between regional and national effects could be settled in favour of region if spatially specific problems like local unemployment or environmental pollution with woodwaste could be solved by introduction of CBWF blocks production.

\section{References}

1. D. Małaszkiewicz, M. Sztukowska, MATEC Web of Conferences, 174, 02005 (2018) DOI: $10.1051 /$ matecconf/201817402005

2. G. Philippidis, A. I. Sanjuán López, E. Ferrari, R. M'barek, Spanish Journal of Agricultural Research, 12, 913-926 (2014)

3. R.P. Dahal, J. E. Henderson, I. A. Munn, Forest products journal, 65(7), 372-380 (2015)

4. URL: http://krl.gks.ru/wps/wcm/connect/rosstat_ts/krl/ru/statistics/prices/ 
5. URL: http://krl.gks.ru/wps/wcm/connect/rosstat_ts/krl/ru/statistics/employment/

6. URL: https://www.nalog.ru/rn77/taxation/taxes/

7. URL:http://krl.gks.ru/wps/wcm/connect/rosstat_ts/krl/ru/statistics/standards_of_life/

8. URL: http://fm.minfin.karelia.ru/FM/reports/FO_0002_0008/Default.aspx

9. C. Leonard, Foresight and STI Governance, 10(3), 30-33 (2016)

10. R. Crescenzi, M. Giua, Environment and Planning A, 48(11), 2340-2357 (2016)

11. C. Cambero, T. Sowlati, Renewable and Sustainable Energy Reviews, 36, 62-73 (2014) 